\title{
The Optimal Step Toll Scheme for Heavily Congested Ports
}

\author{
Chen-Hsiu Laih \\ Associate Professor, Chairperson, Department of Merchant Marine, National Taiwan Ocean University, 2, Pei-Ning \\ Road, Keelung, Taiwan., chlaih@mail.ntou.edu.tw \\ Kuang-Che Hung \\ Graduate Student, Master Program in Department of Merchant Marine, National Taiwan Ocean University, 2, Pei-Ning \\ Road, Keelung, Taiwan.E-mail:m91710005@mail.ntou.edu.tw.
}

Follow this and additional works at: https://jmstt.ntou.edu.tw/journal

Part of the Business Commons

\section{Recommended Citation}

Laih, Chen-Hsiu and Hung, Kuang-Che (2004) "The Optimal Step Toll Scheme for Heavily Congested Ports," Journal of Marine Science and Technology. Vol. 12: Iss. 1, Article 3.

DOI: $10.51400 / 2709-6998.2216$

Available at: https://jmstt.ntou.edu.tw/journal/vol12/iss1/3

This Research Article is brought to you for free and open access by Journal of Marine Science and Technology. It has been accepted for inclusion in Journal of Marine Science and Technology by an authorized editor of Journal of Marine Science and Technology. 


\title{
THE OPTIMAL STEP TOLL SCHEME FOR HEAVILY CONGESTED PORTS
}

\author{
Chen-Hsiu Laih* and Kuang-Che Hung**
}

Key words: congestion tolls, queuing, container ships, departure time.

\begin{abstract}
This paper considers the time cost incurred when a container ship is queuing to enter a port and when a container ship arrives at the port ahead of or behind the scheduled time. With this regard, we derive a series of the optimal congestion toll scheme, in order to eliminate or decrease the port congestion. By means of collecting congestion tolls, container ships' departure schedules can be rationally altered, and consequently disperse container ships' arrival times at the destination port as well as eliminate or decrease container ships' queuing times for port entry. Next, we use the sense of economic equilibrium to derive the consequent changes of container ships' departure schedules after collecting congestion tolls. These results help predict ship owners' departure behaviors under the optimal step toll scheme.
\end{abstract}

\section{INTRODUCTION}

Queuing often develops in front of the entry to a road bottleneck during the commuting rush hour. The model of pricing a queuing bottleneck first developed by Vickrey [13] and extended by Braid [3], Arnott et al. [1, 2], Tabuchi [12], Laih [4-11], and Yang and Meng [14]. Among these researches, Laih [4] first developed a flexible pricing mechanism including the optimal single- and multi-step tolls to relieve commuting queuing in the morning at a road bottleneck. Laih [11] also provides a methodological framework to forecast commuter behavior changes from the no toll case to both the optimal single- and multi-step toll cases. Applying these considerations, this paper derives a series of the optimal toll schemes to a congested harbor. With these pricing schemes, ships' queuing time for port entry can

Paper Submitted 09/08/03, Accepted 12/15/03. Author for Correspondence: Chen-Hsiu Laih.E-mail: chlaih@mail.ntou.edu.tw.

*Associate Professor, Chairperson, Department of Merchant Marine, National Taiwan Ocean University, 2, Pei-Ning Road, Keelung, Taiwan. **Graduate Student, Master Program in Department of Merchant Marine, National Taiwan Ocean University, 2, Pei-Ning Road, Keelung, Taiwan. E-mail:m91710005@mail.ntou.edu.tw. be eliminated or diminished. This paper also investigates the consequent changes of merchant ships' departure schedule after collecting congestion tolls. All of these are important issues for the ship owner and the harbor bureau if pricing a congested harbor is considered by the authorities. Also, they are issues that have not been discussed previously.

When a regular container ship departs from a harbor and moves on to the next appointed berth, the shipmaster will notify the marine company the time of arrival with a telegraphic message. This procedure is for the convenience of the company to carry out the necessary dispatch steps. If the containership arrives at the port during congestion, the harbor officers will guide it to wait at general anchorage. When a vacancy at the berth becomes available, a pilot will shepherd it to the berth where it unloads and loads. This situation is very similar to the traffic congestion on the road. At the road bottleneck, every car has to queue before entering the road bottleneck. From an economic point of view, we can minimize the queuing by collecting congestion tolls. Hence, if the same applies to the arrival of containerships at a harbor, a certain degree of effectiveness should be achieved.

This paper will derive a framework of collecting congestion tolls that applies to all general congested commercial harbors. The content includes the optimal time-varying toll and the optimal step toll schemes. We will then advice related offices this strategy. Port congestion pricing leads to efficient use of berth especially during the crowded season. The ship owner may not consider anchoring their ships at other ports that do not implement the port congestion pricing because of the two reasons. The first is the port congestion pricing reduces ships' waiting time at general anchorage. The second is the ship may not be willing to anchor other ports for some inconvenience reasons, e.g., the voyage distance to other ports may be too long. Therefore, most of externalities cannot be internalized in free competition marine market. Port congestion pricing seems as much important as road congestion pricing.

Here we will review some literatures related to 
pricing a queuing bottleneck. Laih [4] looked into the model of charging at queuing road bottleneck and used the static equilibrium analytical method to develop a series of the optimal and sub-optimal step toll schemes. This development helps to achieve the goal of collecting tolls in an easy and flexible way. The best part about the ways of charging step tolls is that it provides decision makers a set of collecting toll framework with selectivity when trying to minimize negative effects of congestion. Furthermore, considering the ways of charging the step toll scheme have blind spots existed in the overall benefit of both the supply and demand sides and in practice, Laih [5] investigated the increased or decreased cost functions of both the supply (Government) and the demand (auto-commuters) in respond to variation of number of charging steps, during the application of the optimal step toll scheme at a queuing road bottleneck. Under the principle of minimum cost of both sides, he derived the optimal charging steps to the optimal step toll scheme. This derivation maximized the social welfare and also provides the basis for policy makers in practice. However, the two thesis mentioned above did not explore the variation of auto-commuters' departure before and after the period of congestion charge.

In order to obtain the behavioral variation in departure before and after charging the tolls, Laih [6] provides a way to prove the effectiveness of shortening entire queuing time of all auto-commuters to $1 / 2$ or $2 / 3$ of the original, with the premises that the ways of collecting the optimal single- and double-step tolls are in equilibrium. However, this study only displays a simple outcome of dispersing auto-commuters' departure rates after the application of the optimal single- and double-step toll schemes. It was not known clearly where an auto-commuter, who departed before period of charging these tolls, went after that period. As a result, Laih [7, 8] utilizes the dynamic equilibrium analytical method to derive auto-commuters' moving tracks of departure time before and after the application of collecting the optimal single- and double-step toll schemes. Next, Laih [9] derived the optimal number of pricing steps, which minimizes the total costs for the demand and supply sides, for the step toll scheme implemented at a queuing road bottleneck. These outcomes not only improve the theoretical model of the step toll scheme, but also provide the authorities a rule to operate the optimal step toll in practice.

Moreover, Laih et al. [10] derived the auto-commuters' related time values when queuing during the morning rush hour, using the analytical methods of utility functions. This paper set the phenomenon of auto-commuters' cars queuing at the entry to a road bottleneck as the research background, used the theory of auto-commuters pursuing maximized utility as the base, and at the same time, takes account of various constraints, such as time and income. Then in accordance with the late arrival and early arrival models depending on the time of arrival at work place, each of the related time values during periods of auto-commuting was derived. The results of this research showed that: the unit time value of late arrival is equal to difference between the punishment cost of unit time value of late arrival and the unit time value of leisure; the unit time value of early arrival equals to the unit time value of leisure; unit time value of queuing equals to the sum of unit time value of leisure and unit traveling cost.

Recently, Laih [11] expanded the analysis of the optimal single and double steps to nth number $(n=$ $1,2,3, \ldots)$ of charging steps. It was realized that when the charging steps increased one by one after detailed derivation, the framework of the optimal step toll, the related equilibrium costs, the equilibrium departure rates and moving tracks of departure time of auto-commuters had all shown regular variation. These complete and regular information not only facilitate policy makers for the application of the optimal step toll scheme, it can also be used to predict the entire auto-commuters' behavior in the system of toll collection.

\section{THE MODEL FRAMEWORK AND EQUILIBRIUM RESULTS IN THE OPTIMAL TIME-VARYING TOLL AND SINGLE-STEP TOLL CASES}

\section{Derivation of the Non Toll Equilibrium and the Optimal Time-Varying Toll Scheme}

In order to simplify the model in this paper, thus the following conditions are assumed in accordance with the research targets:

1. The assumed background of this paper is that there is no berth available and all admitted container ships have to wait at the general anchorage until the pilot comes to shepherd the waiting ships.

2. A large amount of ships will enter the port at certain periods of time regularly during the year causing congestion. This may be a result of local demand or increase in demand attracting more ships into the port, for example, during harvest time. These conditions are traceable and cyclic.

3. Apart from the cost of queuing during congestion, the cost structure of this model also covers that of schedule delay, such as early or late arrival. In order to simplify this model, we assume the time cost as a linear function. 
4. Other than delay caused by waiting at the general anchorage, there is no delay occurred during the voyage. Hence the cost during the no delay voyage is fixed and is not included in the discussion.

Assuming there is a periodically congested port, and the port office will place a congestion charge in order to relieve the situation. The problems relating to ships entering the port in this model can de described as follow: there is now an existing destination port and every set time there will be a fixed number $N$ of container ships leaving from departure ports $i$ for a certain destination port. The destination port however can only provide service for s number of ships and $N>s$. The sailing time of ship $(T)$ is equal to distance traveled divided by sailing velocity, hence the average arrival frequency at the destination port is $T_{i} / N_{i}$. The conditional terms of queuing time at the general anchorage is defined as when the average arrival frequency is smaller than the operation time $\left(T_{b}\right)$ of a single ship at the destination port. In fact, queuing may still happen even though the above definition is satisfied. The queuing time at the general anchorage should be the function of the number and the utilization ratio of all berths. In order to simplify the model, however, we ignore this function in the following discussion.

This model defines three situations: late arrival $\left(t+T_{x}(t)>t^{*}\right)$, early arrival $\left(t+T_{x}(t)<t^{*}\right)$ and on-time $\left(t+T_{x}(t)=t^{*}\right)$ by comparing the time of a ship arriving at the port and finishing all the unloading jobs, with the liner scheduled time. Among these three situations, $t$ is the time point when a ship leaves the port of departure (all the ships left from this port will be queuing at the port of destination), $T_{x}(t)$ is the length of queuing time at the the general anchorage and varies according to the time of departure, $t+T_{x}(t)$ stands for time required for completed unloading. $t^{*}$ is the scheduled unloading time. In addition, $t^{*}$ represents the anticipated arrival time of the maximal queuing time causing delay. $T_{y}(t)$ is the time length of early arrival, which is $t^{*}-\left(t+T_{x}(t)\right)$, which means that ships arrive at the port before the scheduled time. $T_{z}(t)$ is the time length of late arrival with formula $\left(t+T_{x}(t)\right)-t^{*}$, which means that ships arrive at the port after the scheduled time.

Since there is no other delay during the period of voyage, the time point $t_{1}$ (i.e. the starting time of queuing at the general anchorage) will vary in accordance with the departure time of the ship. With regard to the definition of the finishing time of queuing at the general anchorage $t_{2}$, it depends on the time length required to disperse all queuing ships, the number of ships waiting to enter the port, the number of ships that can be serviced and the entire operation time of a ship at the port of destination in average.
The time parameters of this model are defined as below:

1. Queuing cost per unit time: the necessary cost in average of every unit time before a pilot comes to the general anchorage to shepherd the ship. We assign symbol $x$ for this value which consists of personnel expense, depreciation cost of ships, expense for repairing, insurance fee, interests, petrol fee for maintenances and desalination fee. These expenses are indispensable while ships anchor at the general anchorage area.

2. Cost of early arrival: goods arriving at the destination port early means the overall sailing time is shortened, and the ship has to lengthen her port staying time to match the next scheduled departure time. The cost of port charge to early arrival ship per unit time is set as $y$.

3. Cost of late arrival: when merchandise arrives late, the ship owner will possibly bear the increased cost for unloading, which may include increased costs for hardware apparatus and cost of port workers. Furthermore, it may experience the cancellation of the next scheduled port of call and an enormous amount of transit fee may arise as a result. The cost of late arrival per unit time is symbolized by $z$.

Combining all the above costs per unit time and their effective time, we obtain the following target functions of minimizing the total cost $(C(t))$ :

\section{Minimum}

$$
C(t)=x \cdot T_{x}(t)+y \cdot T_{y}(t)+z \cdot T_{z}(t)
$$

Where $t_{1} \leq t \leq t_{2}$

Classifying the three situations: on time, early arrival and late arrival, we obtain the following equations:

On time situation:

$$
C(t)=x \cdot T_{x}(t)
$$

Among which $t+T_{x}(t)=t^{*}$

Early arrival situation:

$$
\begin{aligned}
C(t) & =x \cdot T_{x}(t)+y \cdot T_{y}(t) \\
& =x \cdot T_{x}(t)+y \cdot\left[t^{*}-\left(t+T_{x}(t)\right)\right]
\end{aligned}
$$

Among which $t_{1} \leq \mathrm{t}+T_{x}(t)<t^{*}$

Late arrival situation: 


$$
\begin{aligned}
C(t) & =x \cdot T_{x}(t)+z \cdot T_{z}(t) \\
& =x \cdot T_{x}(t)+z \cdot\left[\left(t+T_{x}(t)\right)-t^{*}\right]
\end{aligned}
$$

Among which $t^{*}<t+T_{x}(t) \leq t_{2}$

Due to the principle of minimizing the total cost, which is followed by all ships, the total cost per unit time has to be the same during $t_{1} \leq t \leq t_{2}$ no matter what the situation is. Hence the equilibrium condition is $d C /$ $d t=0$. In accordance with this principle, we differentiate (2), (3) and (4) with $t$.

On time situation:

Unable to differentiate (2) because this situation is one point in time, $(\tilde{t})$, which is defined as the departure time in order to complete unloading on $t^{*}$.

Early arrival situation:

$$
\frac{d C}{d t}=(x-y) \frac{d T_{x}}{d t}-y=0
$$

Among which $t_{1} \leq t+T_{x}(t)<t^{*}$

Late arrival situation:

$$
\frac{d C}{d t}=(x+z) \frac{d T_{x}}{d t}+z=0
$$

Among which $t^{*}<t+T_{x}(t) \leq t_{2}$

In order to investigate the relationship between queuing time length and the moment ships depart, we arranged (6) and (7) separately and obtained:

Early arrival situation:

$$
\frac{d T_{x}(t)}{d t}=\frac{y}{x-y}
$$

Among which $t_{1} \leq t+T_{x}(t)<t^{*}$

Late arrival situation:

$$
\frac{d T_{x}(t)}{d t}=\frac{-z}{x+z}
$$

Among which $t^{*}<t+T_{x}(t) \leq t_{2}$

Generally speaking, $x, y$ and $\mathrm{z}$ are positive, then we can get the slope of the linear relationship between $T_{x}(t)$ and $t$. Thus we assayed positive relationship occurs in early arrival situation and negative when ships arrive late. From this relationship, the equilibrium queuing time length can be easily calculated. $z^{\text {Take }} t^{*}$ for example, can be obtained as $\left(t^{*}-t_{2}\right) \cdot \frac{-z}{x+z}$. The length of queuing time depends on the number of ships waiting to enter the port, the number of ships that can be serviced and their total operating time at the port of destination in average. For example, if there are 50 ships queuing but the port can only provide service for 10 ships with each operating 5 hours in average, then the time length required to disperse all queuing ships is $50 \div 10 \times 5=25$ (hours). Therefore, we have the following equation:

$$
t_{2}-t_{1}=\frac{N}{s} \cdot T_{b}
$$

$N$ is the number of ships waiting to enter the port, $s$ is the number of ships that can be serviced and $T_{b}$ is their total operating time at the port of destination in average. Then based on the definitions of $\tilde{t}$ and $t^{*}$, we are able to list two equations as shown below:

$$
\begin{aligned}
& \tilde{t}+\frac{y}{x-y}\left(\tilde{t}-t_{1}\right)=t^{*} \\
& \tilde{t}-\frac{z}{x+z}\left(\tilde{t}-t_{2}\right)=t^{*}
\end{aligned}
$$

After rearranging (10), (11) and (12), we have

$$
\begin{aligned}
& t_{1}=t^{*}-\frac{z}{y+z}\left(\frac{N}{S} \cdot T_{b}\right) \\
& t_{2}=t^{*}+\frac{y}{y+z}\left(\frac{N}{S} \cdot T_{b}\right) \\
& \tilde{t}=t^{*}-\frac{y \cdot z}{x(y+z)}\left(\frac{N}{s} \cdot T_{b}\right)
\end{aligned}
$$

Substituting (15) into (2), we obtain the equilibrium total cost, $C^{e}$, for each ship:

$$
C^{e}=\frac{y \cdot z}{y+z}\left(\frac{N}{s} \cdot T_{b}\right)
$$

The optimal time varying toll $\Omega(t)$ is derived by using congestion tolls collected to replace all queuing costs incurred at the general anchorage under the situation that all ships remain their equilibrium total cost $C^{e}$. In order to attain such an objective, it is then necessary to impose a series of tolls, $\Omega(t)$, that results in $T_{x}(t)=0$ and $C(t)=C^{e}$ for all $t$ in (2), (3) and (4). Thus substituting (16) into (2), (3) and (4), we obtain a series of the optimal time varying toll, $\Omega(t)$, as listed in details below:

On time situation:

$$
\Omega(t)=C^{e}=\frac{y \cdot z}{y+z}\left(\frac{N}{S} \cdot T_{b}\right)
$$

Among which $t+T_{x}(t)=t^{*}$

Early arrival situation:

$$
\Omega(t)=C^{e}-y \cdot\left[t^{*}-\left(t+T_{x}(t)\right)\right]
$$


Among which $t_{1} \leq \mathrm{t}+T_{x}(t)<t^{*}$

Late arrival situation:

$$
\Omega(t)=C^{e}-z \cdot\left[\left(t+T_{x}(t)\right)-t^{*}\right]
$$

Among which $t^{*}<t+T_{x}(t) \leq t_{2}$

The shape of the optimal time-varying toll scheme is triangular because of continuously changeable

charges throughout the queuing period $\left[t_{1}, t_{2}\right]$. The maximum optimal time-varying toll is located at $t^{*}$. The slope for (18) during $\left[t_{1}, t^{*}\right)$ is always smaller than the slope for (19) during $\left(t^{*}, t_{2}\right]$ since $y<z$. The optimal time-varying toll is capable of eliminating queuing time completely, but has practical difficulties because it requires continuously changeable charges. Because of these difficulties, a step toll scheme is considered as an alternative to reduce queuing time. The single- and multi-step tolls inscribed in the optimal fine toll triangle will be discussed in the following Sections to reduce the queuing time to a desired level.

\section{Derivation of the Optimal Single-Step Toll Scheme}

The single-step toll scheme is collected from ships arriving at the general anchorage during a chosen period of time of congestion. The range of this toll scheme has to agree with the equilibrium principle, i.e. it has to fall within two sides of the optimal time-varying toll triangular. Therefore the toll level $(\delta)$ is the height of the inscribed rectangle within the triangle and the length of charging period is the width. Efficiency of eliminating queuing is the ratio between the area of the inscribed rectangle and that of the triangle. Table 1 shows some symbols and their meanings used in the optimal singlestep toll scheme. Please Note that $t_{1}$ is now assumed to locate on the origin (i.e., $t_{1}=0$ ) for the purpose of simplifying all values listed in Table 1 . Therefore the values of $t_{1}$ and $t_{2}$ listed in Table 1 are $\left(t^{*}-\frac{z}{y+z}\left(\frac{N}{s} T_{b}\right)\right)$ earlier than those first appeared in (13) and (14).

Under the equilibrium state, all the different departure time must correspond to the same total cost $C^{e}$. It is explained in two different situations as follow:

(I). Early arrival $\left(t_{1} \leq t \leq \hat{t}\right)$ : all the incoming ships to a port enter one after another in a queue, so the difference of early arrival cost between a ship and the one behind is a fixed value, which is operation time at port $T_{b}$ multiplied by early arrival cost $y$, i.e. $y \cdot T_{b}$, and these two ships have to bear the same total cost $C^{e}$ under equilibrium state. During the process of calculating $C^{e}$, $y \cdot T_{b}$ is a constant and is not affected by $t$ or $T_{x}(t)$, therefore in this model the early arrival cost of the two ships described earlier is considered as the same. Let $t^{+}$ be the start charging time in the optimal step toll scheme, and then we can imagine that the last ship without paying any toll before $t^{+}$and the first toll-paying ship at the moment $t^{+}$enter the port one after another. Because the latter one does not incur any queuing cost, the queuing cost to the former ship consequently is equal to the collected toll, and once the former ship arrived at the destination port, there are no other ships arrived during a certain period $\left(t^{+}-t^{\prime}=\delta / x\right)$ until the latter ship arrived. After the queuing phenomenon at general anchorage is cleared, ships choosing to pay tolls will begin to arrive at the port of destination. For this reason, the early arrival situation can be categorized into three different time periods: non-toll paying period $\left(t_{1} \leq t<t^{\prime}\right)$, no ships setting off period $\left(t^{\prime} \leq t<t^{+}\right)$and toll-paying period $\left(t^{+}\right.$ $\leq t \leq \hat{t}$ ).

(a) $t_{1} \leq t<t^{\prime}$ (Non toll-paying time period)

$$
\begin{aligned}
& C(\mathrm{t})=x \cdot T_{x}(t)+y \cdot\left[t^{*}-\left(t+T_{x}(t)\right)\right] \\
& C\left(t_{1}\right)=y \cdot t^{*}
\end{aligned}
$$

Since (20) must be equal to (21) for the equilibrium purpose, we obtain

$$
x T_{x}^{e}(t)=\frac{x \cdot y \cdot t}{x-y}
$$

\begin{tabular}{|c|c|c|}
\hline Symbols & Meanings & Values \\
\hline$t_{1}$ & $\begin{array}{l}\text { Beginning time point } \\
\text { of port congestion }\end{array}$ & $t^{*}-\frac{z}{y+z}\left(\frac{N}{s} T_{b}\right)$ \\
\hline$t^{+}$ & $\begin{array}{l}\text { Starting time point } \\
\text { of toll collection }\end{array}$ & $t^{*}-\frac{1}{2} \frac{z}{y+z}\left(\frac{N}{s} T_{b}\right)$ \\
\hline$t^{*}$ & $\begin{array}{l}\text { Liner scheduled } \\
\text { time point }\end{array}$ & Set values \\
\hline$t^{-}$ & $\begin{array}{l}\text { End time point of } \\
\text { toll collection }\end{array}$ & $t^{*}+\frac{1}{2} \frac{y}{y+z}\left(\frac{N}{s} T_{b}\right)$ \\
\hline$t_{2}$ & $\begin{array}{l}\text { Finishing time point } \\
\text { of port congestion }\end{array}$ & $t^{*}+\frac{y}{y+z}\left(\frac{N}{s} T_{b}\right)$ \\
\hline$\Omega\left(t^{*}\right)$ & Equilibrium total cost, $C_{e}$ & $\frac{y \cdot z}{y+z}\left(\frac{N}{s} T_{b}\right)$ \\
\hline$\Omega\left(t^{+}\right)=\Omega$ & $\begin{array}{l}\text { Toll collected, which is } \\
1 / 2 \text { of } \Omega\left(t^{*}\right)\end{array}$ & $\frac{1}{2} \frac{y \cdot z}{y+z}\left(\frac{N}{s} T_{b}\right)$ \\
\hline \multicolumn{2}{|c|}{$\begin{array}{c}\text { Effectiveness of } \\
\text { eliminating queuing }\end{array}$} & $1 / 2$ \\
\hline
\end{tabular}

The slope of (22) is $\frac{x \cdot y}{x-y}$, this represents that the

Table 1. The optimal single-step toll scheme 
equilibrium queuing cost $\left(x T_{x}{ }^{e}(t)\right)$ line of this time period in the optimal single-step toll case coincides with that of early arrival zone in the original no toll case. $t^{\prime}$ is the starting time point when no ship departs and its value is $\frac{z(x-y)}{2 x(y+z)} \frac{N}{S} T_{b}$.

(b) $t^{\prime} \leq t<t^{+}$(Non toll-paying time period)

No ships depart. This stage clearly disperses all accumulated ships queue at general anchorage, and its time length is $\delta / x$.

(c) $t^{+} \leq t \leq \hat{t}$ (Toll-paying time period)

$$
\begin{aligned}
& C(t)=x T_{x}(t)+y \cdot\left[t^{*}-\left(t+T_{x}(t)\right)\right]+\delta \\
& C\left(t_{q}\right)=y \cdot\left(t^{*}-t_{1}\right)
\end{aligned}
$$

(23) equals (24) for the equilibrium purpose, thus

$$
x T_{x}^{e}(t)=\frac{x y \cdot t-x \delta}{x-y}
$$

Its slope is also $\frac{x y}{x-y}$, which means the equilibrium queuing cost line of this time period after charging the toll, $\delta$, is parallel to that of early arrival zone in the original no toll case. $\hat{t}$ is the departure time point for ships to arrive on time after collecting the toll, and its value is $\frac{z(x-y)}{2 x(y+z)} \frac{N}{S} T_{b}$.

(II). Late Arrival ( $\hat{t}<t \leq t_{2}$ ): let $t^{-}$be the finish charging time in the optimal step toll scheme, then the last toll-paying ship before time $t^{-}$and the one after that without paying the toll enter the port one after another. Therefore in this model, the late arrival costs of these two ships are taken as the same. Since they both have the same equilibrium total cost $C^{e}$, hence the equilibrium queuing cost to the first non toll-paying ship after toll-collection time period finishes is equal to the collected toll. This situation means the first ship that does not have to pay the toll after toll-collection time period finishes will wait at the general anchorage area, and only asks for admission into the port until time $t^{-}$. For this reason, the late arrival situation can be classified into three time periods: toll-paying period $\left(\hat{t} \leq t<t^{-}\right)$, avoiding toll-paying period $\left(t^{\#} \leq t<t^{-}\right)$and non tollpaying period $\left(t^{-} \leq t \leq t_{2}\right)$.

(d) $\hat{t}<t \leq t^{\#}$ (Toll-paying time period)

$$
\begin{aligned}
& C(t)=x T_{x}(t)+z\left[\left(t+T_{x}(t)\right)-t^{*}\right]+\delta \\
& C\left(t_{2}\right)=z\left(t_{2}-t^{*}\right)
\end{aligned}
$$

(26) equals (27) for the equilibrium purpose, therefore

$$
x T_{x}^{e}(t)=\frac{x z\left(t_{2}-t\right)-x \delta}{x+z}
$$

The slope of (28) is $\frac{-x z}{x+z}$, this represents that the line of the equilibrium queuing cost during this time period in the optimal single-step toll case is parallel to that during the late arrival zone in the original no toll case. $t^{\#}$ is the starting time point of avoiding congestion charge and its value is $\frac{2 x z+x y-y z}{2 x(y+z)} \cdot \frac{N}{s} \cdot T_{b}$.

(e) $t^{\#} \leq t<t^{-}$(Including toll-paying and avoiding tollpaying time period)

This time period comprises two parts. One is of normal toll-paying ships, whose equilibrium queuing cost is calculated in the same way as in time period (a), and is parallel to the equilibrium queuing cost during late arrival time zone in the original no toll case. The other part is the avoiding toll-paying ships, the slope of their equilibrium queuing costs between $t^{\#}$ and $t^{-}$is $-x$, and the slope of their equilibrium queuing costs after $t^{-}$ on the other hand is $\frac{x^{2}}{x+z}$.

(f) $t^{-} \leq t \leq t_{2}$ (Non toll-paying time period)

$$
\begin{aligned}
& C(t)=x T_{x}(t)+z\left[\left(t+T_{x}(t)\right)-t^{*}\right] \\
& C\left(t_{2}\right)=z\left(t_{2}-t^{*}\right)
\end{aligned}
$$

For the equilibrium purpose, we obtain

$$
x T_{x}^{e}(t)=\frac{x z\left(t_{2}-t\right)}{x+z}
$$

This represents that the equilibrium queuing cost

Table 2. Determined time points of altering ships' departure times under the optimal single-step toll scheme

\begin{tabular}{clc}
\hline Symbols & \multicolumn{1}{c}{ Meanings } & \multicolumn{1}{c}{ Values } \\
\hline$t^{\prime}$ & $\begin{array}{l}\text { Starting time when no } \\
\text { ship leaves before toll } \\
\text { collection } \\
\hat{t}\end{array}$ & $\frac{z(x-y)}{2 x(y+z)} \frac{N}{s} T_{b}$ \\
& $\begin{array}{l}\text { Departure time in order } \\
\text { to arrive the port on time } \\
\text { after application of }\end{array}$ & $\frac{z(2 x-y)}{2 x(y+z)} \frac{N}{s} T_{b}$ \\
& $\begin{array}{l}\text { congestion toll collection } \\
\text { Starting time of queuing } \\
t^{\#}\end{array}$ & $\frac{2 x z+x y-y z}{2 x(y+z)} \frac{N}{s} T_{b}$ \\
& $\begin{array}{l}\text { when avoiding toll } \\
\text { collection }\end{array}$ & \\
\hline
\end{tabular}


Table 3. The optimal double-step toll scheme

\begin{tabular}{|c|c|c|}
\hline Symbols & Meanings & Values \\
\hline$t_{1}$ & $\begin{array}{l}\text { Beginning time point of } \\
\text { port congestion }\end{array}$ & $t^{*}-\frac{z}{y+z}\left(\frac{N}{S} T_{b}\right)$ \\
\hline$t^{+}$ & $\begin{array}{l}\text { Starting time point of } \\
\text { lower toll collection }\end{array}$ & $t^{*}-\frac{2}{3} \frac{z}{y+z}\left(\frac{N}{s} T_{b}\right)$ \\
\hline$t^{++}$ & $\begin{array}{l}\text { Starting time point of } \\
\text { higher toll collection }\end{array}$ & $t^{*}-\frac{1}{3} \frac{z}{y+z}\left(\frac{N}{s} T_{b}\right)$ \\
\hline$t^{*}$ & $\begin{array}{l}\text { Liner scheduled time } \\
\text { point }\end{array}$ & Set values \\
\hline$t^{-}$ & $\begin{array}{l}\text { End time point of lower } \\
\text { toll collection }\end{array}$ & $t^{*}+\frac{1}{3} \frac{y}{y+z}\left(\frac{N}{s} T_{b}\right)$ \\
\hline$t^{-}$ & $\begin{array}{l}\text { End time point of higher } \\
\text { toll collection }\end{array}$ & $t^{*}+\frac{2}{3} \frac{y}{y+z}\left(\frac{N}{s} T_{b}\right)$ \\
\hline$t_{2}$ & $\begin{array}{l}\text { Finishing time point of } \\
\text { port congestion }\end{array}$ & $t^{*}+\frac{y}{y+z}\left(\frac{N}{s} T_{b}\right)$ \\
\hline$\Omega\left(t^{*}\right)$ & Equilibrium total cost, $C_{e}$ & $\frac{y z}{y+z}\left(\frac{N}{s} T_{b}\right)$ \\
\hline$\Omega\left(t^{+}\right)=\Omega$ & $\begin{array}{l}\text { Lower toll collected, } \\
\text { which is } 1 / 3 \text { of } \Omega\left(t^{*}\right)\end{array}$ & $\frac{1}{3} \frac{y z}{y+z}\left(\frac{N}{s} T_{b}\right)$ \\
\hline$\Omega\left(t^{++}\right)=\Omega$ & $\begin{array}{l}\text { Higher toll collected, } \\
\text { which is } 2 / 3 \text { of } \Omega\left(t^{*}\right)\end{array}$ & $\frac{2}{3} \frac{y z}{y+z}\left(\frac{N}{s} T_{b}\right)$ \\
\hline & $\begin{array}{l}\text { ctiveness of } \\
\text { ating queuing }\end{array}$ & $2 / 3$ \\
\hline
\end{tabular}

line during this time period in the optimal single-step toll case coincides with that during the late arrival time zone in the original no toll case.

Based on the above derivation, the determined time points under the optimal single-step toll scheme are shown in Table 2.

After comparing the above equilibrium queuing costs in the optimal single-step toll case with the overall equilibrium queuing costs in the original no toll case, it is found that the departure time of different ships evidently spreads out and queuing is eliminated by $50 \%$.

\section{THE EQUILIBRIUM RESULTS IN THE OPTIMAL MULTI-STEP TOLL CASE}

\section{The Optimal Double-Step Toll Scheme}

The optimal single-step toll scheme can only diminish queuing by $50 \%$, so if the port office is seeking a more ideal way, the number of steps of toll collection needs to be increased. The double-step toll scheme means collecting lower toll for a particular queuing time period, then a relatively higher toll is collected during other period. Afterwards, the toll level returns to the original lower one until the charging time period is over.
Table 4. Determined time points of altering ships' departure times under the optimal double-step toll scheme

\begin{tabular}{|c|c|c|}
\hline Symbols & Meanings & Values \\
\hline$t^{\prime}$ & $\begin{array}{l}\text { Starting time when no } \\
\text { ship leaves before lower } \\
\text { toll collection }\end{array}$ & $\frac{z(x-y)}{3 x(y+z)} \frac{N}{s} T_{b}$ \\
\hline$t^{\prime \prime}$ & $\begin{array}{l}\text { Starting time when no } \\
\text { ship leaves before higher }\end{array}$ & $\frac{z(2 x-y)}{3 x(y+z)} \frac{N}{s} T_{b}$ \\
\hline$\hat{t}$ & $\begin{array}{l}\text { Departure time in order } \\
\text { to arrive the port on time } \\
\text { after application of }\end{array}$ & $\frac{z(3 x-y)}{3 x(y+z)} \frac{N}{S} T_{b}$ \\
\hline$t^{\#}$ & $\begin{array}{l}\text { congestion toll collection } \\
\text { Starting time of queuing } \\
\text { when avoiding higher }\end{array}$ & $\frac{3 x z+x y-y z}{3 x(y+z)} \frac{N}{s} T_{b}$ \\
\hline$t^{\# \#}$ & $\begin{array}{l}\text { toll collection } \\
\text { Starting time of queuing } \\
\text { when avoiding lower toll } \\
\text { collection }\end{array}$ & $\frac{3 x z+2 x y-y z}{3 x(y+z)} \frac{N}{S} T_{b}$ \\
\hline
\end{tabular}

The effectiveness of eliminating queuing in the doublestep toll scheme is determined by the toll level and the charging time length. Table 3 shows some symbols and their meanings used in the optimal double-step toll scheme.

Under the framework of the optimal double-step toll scheme, analysis of ships' departure time alteration is similar to that of single-step. The early arrival can be separated into 5 stages: non-toll paying period, the first no ships leaving period, lower toll paying period, the second no ships leaving period and higher toll paying period. On the other hand, late arrival situation can also be divided into 5 stages: higher toll paying, lower toll paying in avoiding higher toll paying, lower toll paying, avoiding lower toll paying and non-toll paying. Their determined time points are shown in Table 4.

\section{The Optimal $n$-Step Toll Scheme}

Compared with the optimal single-step toll scheme, the toll collection and the effectiveness of eliminating queuing in multiple steps show an apparent regular trend. It is simple to estimate all equilibrium results in the $n$-steps. When $n$ approaches infinity, the framework of step toll collection will be similar to the optimal timevarying toll scheme. However, as $n$ increases, the number of toll collection steps increases, which means more troubles will arise for the incoming ships. The following Tables 5 and 6 shows the results of the optimal $n$-step toll scheme. 
Table 5. The optimal $n$-step toll scheme

\begin{tabular}{|c|c|c|}
\hline Symbols & Meanings & Values \\
\hline$t_{1}$ & $\begin{array}{l}\text { Starting time point of } \\
\text { port congestion }\end{array}$ & $t^{*}-\frac{z}{y+z}\left(\frac{N}{s} T_{b}\right)$ \\
\hline$t^{+}$ & $\begin{array}{l}\text { Starting time point of the } \\
1 \text { st step toll collection }\end{array}$ & $t^{*}-\frac{n}{n+1} \frac{z}{y+z}\left(\frac{N}{s} T_{b}\right)$ \\
\hline$t^{++}$ & $\begin{array}{l}\text { Starting time point of the } \\
\text { 2nd step toll collection }\end{array}$ & $t^{*}-\frac{n-1}{n+1} \frac{z}{y+z}\left(\frac{N}{s} T_{b}\right)$ \\
\hline$t^{+++}$ & $\begin{array}{l}\text { Starting time point of the } \\
\text { 3rd step toll collection }\end{array}$ & $t^{*}-\frac{n-2}{n+1} \frac{z}{y+z}\left(\frac{N}{s} T_{b}\right)$ \\
\hline : & . & $:$ \\
\hline$t^{n-\cdots}$ & $\begin{array}{l}\text { Starting time point of } \\
(n-1) \text { th step toll } \\
\text { collection }\end{array}$ & $t^{*}-\frac{2}{n+1} \frac{z}{y+z}\left(\frac{N}{s} T_{b}\right)$ \\
\hline$t^{+^{n} \cdots}$ & $\begin{array}{l}\text { Starting time point of } n \text {th } \\
\text { step toll collection }\end{array}$ & $t^{*}-\frac{1}{n+1} \frac{z}{y+z}\left(\frac{N}{s} T_{b}\right)$ \\
\hline$t^{*}$ & $\begin{array}{l}\text { Liner scheduled time } \\
\text { point }\end{array}$ & Set values \\
\hline$t^{-\cdots}$ & $\begin{array}{l}\text { End time point of } n \text {th } \\
\text { step toll collection }\end{array}$ & $t^{*}+\frac{1}{n+1} \frac{y}{y+z}\left(\frac{N}{s} T_{b}\right)$ \\
\hline$t^{n-\cdots}$ & $\begin{array}{l}\text { End time point of }(n-1) \text { th } \\
\text { step toll collection }\end{array}$ & $t^{*}+\frac{2}{n+1} \frac{y}{y+z}\left(\frac{N}{s} T_{b}\right)$ \\
\hline : & . & \\
\hline$t^{--}$ & $\begin{array}{l}\text { End time point of the } 3 \mathrm{rd} \\
\text { step toll collection }\end{array}$ & $t^{*}+\frac{n-2}{n+1} \frac{y}{y+z}\left(\frac{N}{s} T_{b}\right)$ \\
\hline$t^{--}$ & $\begin{array}{l}\text { End time point of the } \\
\text { 2nd step toll collection }\end{array}$ & $t^{*}+\frac{n-1}{n+1} \frac{y}{y+z}\left(\frac{N}{s} T_{b}\right)$ \\
\hline$t^{-}$ & $\begin{array}{l}\text { End time point of the } 1 \mathrm{st} \\
\text { step toll collection }\end{array}$ & $t^{*}+\frac{n}{n+1} \frac{y}{y+z}\left(\frac{N}{s} T_{b}\right)$ \\
\hline$t_{2}$ & $\begin{array}{l}\text { End time point of port } \\
\text { congestion }\end{array}$ & $t^{*}+\frac{y}{y+z}\left(\frac{N}{s} T_{b}\right)$ \\
\hline$\Omega\left(t^{*}\right)$ & Equilibrium total cost, $C^{e}$ & $\frac{y z}{y+z}\left(\frac{N}{s} T_{b}\right)$ \\
\hline $\begin{aligned} & \Omega\left(t^{+}\right) \\
= & \Omega\left(t^{-}\right)\end{aligned}$ & $\begin{array}{l}\text { The } 1 \text { st step toll collected, } \\
\text { which is } 1 /(n+1) \text { of } \Omega\left(t^{*}\right)\end{array}$ & $\frac{1}{n+1} \frac{y z}{y+z}\left(\frac{N}{s} T_{b}\right)$ \\
\hline $\begin{array}{l}\Omega\left(t^{++}\right) \\
=\Omega\left(t^{-}\right)\end{array}$ & $\begin{array}{l}\text { The 2nd step toll } \\
\text { collected, which is }\end{array}$ & $\frac{2}{n+1} \frac{y z}{y+z}\left(\frac{N}{s} T_{b}\right)$ \\
\hline $\begin{aligned} & \Omega\left(t^{+++}\right) \\
= & \Omega\left(t^{--}\right)\end{aligned}$ & $\begin{array}{l}2 /(n+1) \text { of } \Omega\left(t^{*}\right) \\
\text { The 3rd step toll } \\
\text { collected, which is } \\
3 /(n+1) \text { of } \Omega\left(t^{*}\right)\end{array}$ & $\frac{3}{n+1} \frac{y z}{y+z}\left(\frac{N}{s} T_{b}\right)$ \\
\hline $\begin{array}{l}\begin{array}{c}{ }_{n} \\
\end{array} \\
\Omega\left(t^{+\cdots}\right) \\
=\Omega\left(t^{-\cdots}\right)\end{array}$ & $\begin{array}{c}\text { : } \\
\text { The nth step toll collected, }\end{array}$ & $\frac{n}{n+1} \frac{y z}{y+z}\left(\frac{N}{s} T_{b}\right)$ \\
\hline rect & ess of eliminating queuing & $\frac{n}{n+1}$ \\
\hline
\end{tabular}

Table 6. Determined time points of altering ships departure time underthe optimal $n$-step toll scheme

\begin{tabular}{|c|c|c|}
\hline Symbols & Meanings & Values \\
\hline$t^{\prime}$ & $\begin{array}{l}\text { Starting time when no ship } \\
\text { leaves before the } 1 \text { st step }\end{array}$ & $\frac{z(x-y)}{(n+1) x(y+z)} \frac{N}{s} T_{b}$ \\
\hline$t^{\prime \prime}$ & $\begin{array}{l}\text { toll collection } \\
\text { Starting time when no ship } \\
\text { leaves before the } 2 \text { nd step } \\
\text { toll collection }\end{array}$ & $\frac{z(2 x-y)}{(n+1) x(y+z)} \frac{N}{s} T_{b}$ \\
\hline : & : & : \\
\hline$t^{n+\cdots}$ & $\begin{array}{l}\text { Starting time when no ship } \\
\text { leaves before the } n \text {th step }\end{array}$ & $\frac{z(n x-y)}{(n+1) x(y+z)} \frac{N}{s} T_{b}$ \\
\hline$\hat{t}$ & $\begin{array}{l}\text { toll collection } \\
\text { Departure time in order to } \\
\text { arrive the port on time } \\
\text { after application of }\end{array}$ & $\frac{z[(n+1) x-y]}{(n+1) x(y+z)} \frac{N}{s} T_{b}$ \\
\hline$t^{\#}$ & $\begin{array}{l}\text { congestion toll collection } \\
\text { Starting time of queuing } \\
\text { when avoiding } n \text {th step } \\
\text { toll collection }\end{array}$ & $\frac{(n+1) x z+x y-y z}{(n+1) x(y+z)} \frac{N}{S} T_{b}$ \\
\hline : & $:$ & : \\
\hline$t^{n-1}$ & $\begin{array}{l}\text { Starting time of queuing } \\
\text { when avoiding } 2 \text { nd step } \\
\text { toll collection }\end{array}$ & $\frac{(n+1) x z+(n-1) x y-y z}{(n+1) x(y+z)} \frac{N}{S} T_{b}$ \\
\hline$t^{\#{ }^{n} \cdots}$ & $\begin{array}{l}\text { Starting time of queuing } \\
\text { when avoiding } 1 \text { st step } \\
\text { toll collection }\end{array}$ & $\frac{(n+1) x z+n x y-y z}{(n+1) x(y+z)} \frac{N}{s} T_{b}$ \\
\hline
\end{tabular}

\section{CONCLUSIONS}

Ships queuing and waiting at general anchorage to enter the berth under the port congestion situation is similar to the queuing car situation at a road bottleneck. Therefore, this paper adopted the congestion pricing concept on the road to construct a tolling model for ships. The model started with analysis of ships' time costs, and transformed congestion cost into the toll collected for congestion. Further, the port congestion pricing including the optimal time-varying toll and the optimal step toll schemes are derived based on the ratio of congestion cost to be removed in order to relieve the queuing condition at the port.

Next, we use the sense of economic equilibrium to derive the consequent changes of container ships' departure schedules after collecting congestion tolls. We showed that shipís departure time changes after application of toll collection, and their arrival times at port have rationally dispersed to achieve the purpose of relieving port congestion. These results of ships' depar- 
ture time switches help predict ship owners' departure behaviors under the optimal step toll scheme.

It should be noted that the above results are valid only for a simple model that we have developed in this paper. Two deficits in our model that should be improved and modified for the practice purpose are raised as follows. First, queuing time at the general anchorage in this paper is defined as when the average arrival frequency is smaller than the operation time of a single ship at the destination port. In fact, queuing may still happen even though the above definition is satisfied. The queuing time at the general anchorage should be a function of the number and the utilization ratio of all berths. This function has to be considered in the objective cost function to reply real queuing situation. Second, our simple model ignores the ship ownerís revenue or cost variations due to early or late departure, respectively, in the departure port. In order to avoid congestion in the destination port, early or late departure may result in loading revenue shortage or port charge increase, respectively. The revenue and cost variations also have to be considered in the objective cost function to show the ship ownerís real costs under the optimal step toll scheme.

\section{REFERENCES}

1. Arnott, R.J., De Palma A., and Lindsey R., "Economics of a Bottleneck," J. Urban Econ., Vol. 27, pp. 111-130 (1990).

2. Arnott, R.J., De Palma A., and Lindsey R., "A Structural Model of Peak-Load Congestion: A Traffic Bottleneck with Elastic Demand," Am. Econ. Rev., Vol. 83, pp. 161179 (1993).

3. Braid, M., "Uniform versus Peak-Load Pricing of a Bottleneck with Elastic Demand," J. Urban Econ., Vol.
26, pp. 320-327 (1989).

4. Laih, C.H., "Queuing at a Bottleneck with Single- and Multi-Step Tolls," Transp. Res. Vol. 28(A), No. 3, pp. 197-208 (1994).

5. Laih, C.H., "Effect of the Step Toll System on Queuing Removal," J. Feng Chia Univ., Vol. 28, pp. 79-100 (1995).

6. Laih, C.H., Li, M.R., and Tsai, R.W., "Equilibrium Commuter Behaviors under Step Toll Scheme," Transp. Planning J., Vol. 26, No. 4, pp. 593-614 (1997).

7. Laih, C.H., "Economic Analysis of Commuter Behaviors under the Road Pricing," Proceedings of International Conference on Transportation into the Next Millennium, Nanyang Technological University, Singapore, pp. 321-330. (1998).

8. Laih, C.H., "Economic Analysis on Commuter Behavior for Departure Time Change under the Optimal Singleand Double-Step Tolls," Transp. Plan. J., Vol. 29, No. 2, pp. 253-280 (2000).

9. Laih, C.H., "Optimal Pricing Steps of the Step Toll Scheme," Transp. Plan. J., Vol. 30, No. 2, pp. 253-274 (2001).

10. Laih, C.H., Yang, P.C., Tzeng, C.L., and Pai, C.Y., "Modeling the Auto-Commuters' Time Values," Transp. Planning J., Vol. 32, No. 3, pp. 479-492 (2003).

11. Laih, C.H., "Effects of the Optimal Step Toll Scheme on Equilibrium Commuter Behavior," Appl. Econ., Vol. 36, No. 1, pp. 59-81 (2004).

12. Tabuchi, T., "Bottleneck Congestion and Modal Split," J. Urban Econ., Vol. 34, pp. 414-431 (1993).

13. Vickrey, W.S., "Congestion Theory and Transport Investment," Am. Econ. Rev., Vol. 59, pp. 251-261 (1969).

14. Yang, H. and Meng, Q., "Departure Time, Route Choice and Congestion Toll in a Queuing Network with Elastic Demand," Transp. Res., Vol. 32(B), pp. 247-260 (1998). 